\title{
The Main Causes of Mortality in the Respiratory ICU and Infectious diseases Ward of Sina Hospital in Hamadan
}

\section{A R T I C L E I N F O}

Article Type

Original Research

Authors

Fariba keramat, $M D^{1,2}$

Sima Sadat Ahmadinejad, $M D^{3 *}$

Zahra Sanaei, $P h D^{4}$

Ali Saadatmand, $M S C^{1}$

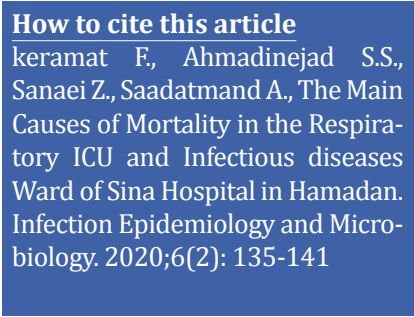

Brucellosis Research Center, Hamadan University of Medical Sciences, Hamadan, Iran.

2 Department of Infectious Diseases, Sina Hospital, Hamadan University of Medical Sciences, Hamadan, Iran. 3 General Practitioner, School of Medicine, Hamadan University of Medical Sciences, Hamadan, Iran. Department of Community Medicine, School of Medicine, Hamadan University of Medical Sciences, Hamadan, Iran.

\section{* Correspondence}

Address: Department of Infectious Diseases, Sina Hospital, Hamadan University of Medical Sciences, Hamadan, Iran. simasadatahmadinejad@gmail.com

\section{Article History}

Received: March 15,2020

Accepted: May 15,2020

Published: June 10,2020

\section{A B S T R A C T}

Aims: Infectious diseases are among the most serious diseases that may lead to death in many parts of the world. This study was conducted to investigate the main causes of mortality among patients hospitalized in the infectious ward and respiratory ICU of Sina hospital in Hamadan.

Materials \& Methods: The medical records of patients hospitalized from March 2012 to March 2017 in the infectious ward and respiratory ICU were investigated, those not surviving during the hospitalization.

Findings: A total of 593 medical records of patients were reviewed, of which 534 cases were enrolled in this study. Among which, 426 (79.8\%) and 108 (20.2\%) cases were related to patients hospitalized in the respiratory ICU and infectious ward, respectively The mortality rate during 2012 to 2016 was calculated as follows: $4.69 \%$ in $2012,6.31 \%$ in $2013,4.68 \%$ in $2014,5.2 \%$ in 2015 , and $5.8 \%$ in 2016. This study results showed that the most common causes of mortality were sepsis $(44.4 \%)$ in the respiratory ICU and pneumonia $(25.3 \%)$ in the infectious ward. The highest rates of case fatality were related to sepsis (237cases, 48.2\%) and pulmonary embolism (15 cases, $44.1 \%$ ).

Conclusions: The present study findings showed that sepsis and pneumonia were the most common causes of death among patients hospitalized in the infectious diseases ward and respiratory ICU; also, sepsis and pulmonary embolism accounted for the highest case fatality rates.

\section{Keywords: Mortality, Infectious diseases, Sepsis, Intensive care unit}

\section{CITATION LINKS}

[1] Kasper DL, Madoff LC. Introduction to infectious ... [2] Gupta I, Guin P. Communicable diseases in the South-East... [3] Boutayeb A, Boutayeb S. The burden of non communicable diseases in ... [4] Lankarani KB, Alavian SM, Peymani P. Health in the Islamic... [5] Wester AL, Dunlop O, Melby KK, Dahle UR, Wyller TB. Age-related... [6] Fernández de la Hoz K, de Mateo S, Regidor E. Trends in infectious... [7] Dore GJ, Li Y, Plant AJ, Kaldor JM. Trends in infectious disease... [8] TavanaeeSani A, Mirkarimi H. Evaluation of etiology of infectious ... [9] Mouton CP, Bazaldua OV, Pierce B, Espino DV. Common infections in older... [10] Armstrong GL, Conn LA, Pinner RW. Trends in infectious disease mortality in the United... [11] Golsha R, Golshah E, Jalali Z, Rajabli N, Roshandel G. Final diagnosis and outcomes in old patients admitted to the infectious diseases ward. Med J Mashhad Univ... [12] Hasibi M, Soudbakhsh A, Abadi Z, Mehdipoor P. Mortality rate of infectious disease in relation to holidays: Three year study in Imam Khomeini... [13] Mahmoudi GA, Astaraki P, Anbari K, Khayatpisheh S. Epidemiolgical survey of mortality rate in patients admitted to Shohada hospital of Khorramabad in... [14] Noorizad S, Tabesh H, Mahdian M, Akbari H, Taghadosi M. Causes of mortality and morbidity in a neurosurgery ICU in... [15] Norman DC, Grahn D, Yoshikawa TT. Fever and aging. J Am Geriatr... [16] Norman DC, Yoshikawa TT. Fever in the elderly. Infect Dis Clin... [17] Almario CV, Metz DC, Haynes K, Yang YX. Risk of community-acquired pneumonia in patients with a diagnosis of pernicious anemia: A population-based retrospective cohort study. Eur J Gastroenterol ... [18] Serraino D, Bidoli E, Piselli P, Angeletti C, Bruzzone S, Pappagallo M, et al. Time trends in infectious disease mortality in Italy: 1999-1969. Epidemiol... [19] Tellioğlu E, Balcı G, Mertoğlu A. Duration of stay of patients with community-acquired pneumonia in influenza season. Turk Thorac... [20] Capelastegui A, España PP, Quintana JM, Gallarreta M, Gorordo I, Esteban C, et al. Declining length of hospital stay for pneumonia and postdischarge outcomes. Am... 


\section{Introduction}

Despite dramatic advances in the treatment and prevention of infectious and communicable diseases in recent decades, they are still considered as one of the main causes of morbidity and debility in human society around the world, especially in developing countries [1-2]. Some communicable diseases that cause high mortality rates, especially in low and middle-income countries, include HIV/AIDS, malaria, tuberculosis, acute respiratory infections, and diarrheal disease [3-5]. However, there are some factors that even make developing countries more expose and vulnerable to communicable diseases, such as geographic, demographic, and socio-economic factors. On the other hand, there are also some common types of none-communicable diseases that mostly affect developing countries, such as cardiovascular diseases, cancer, diabetes, chronic obstructive pulmonary disease, and mental disorders. Many studies have suggested that in countries like Iran and Spain, the major leading causes of death associated with infectious diseases are sepsis and pneumonia ${ }^{[6-7]}$. In Australia, respiratory infections and HIV were reported as the most common causes of death ${ }^{[7]}$. In Mashhad, the most common infectious disease causing hospitalization and death in elderly was reported to be pneumonia ${ }^{[8]}$. Understanding early clinical signs of infectious diseases, such as weakness and cachexia, along with the symptoms of underlying diseases, like cardiopulmonary or renal diseases, is essential in order to prevent disease progression and to reduce mortality rate among patients. Such information improves the timely and accurate diagnosis of the disease and leads to early treatment and prevention of mortality ${ }^{[9]}$.

Objectives: This study was conducted to investigate the causes of mortality in the patients hospitalized in the infectious diseases ward and respiratory ICU of Sina hospital in Hamadan.

\section{Materials and Methods}

In this study, the medical records of 593 patients hospitalized and died during March 2012 to March 2017 in the infectious diseases ward and respiratory ICU of Sina hospital in Hamadan, Iran were evaluated. This study was approved by the Ethics Committee of Hamadan University of Medical Sciences (Ethical code: IR.UMSHA.REC.1396.119).

All information about the participants, including demographic characteristics (age, sex), causes of mortality, underlying illnesses, definitive diagnosis, place of residence, and duration of hospitalization were extracted from the patient's medical records and death certificate and entered into the designed chart.

The patients' mortality rate was calculated for each year along with the case fatality rates for common infectious diseases. Incomplete medical records were excluded from the study. Data were analyzed using SPSS software Version 16.0. Student's T-test was used to assess whether there was a statistically significant difference between patients who died due to specific medical conditions. Chi-squared test was used to evaluate the potential difference between different factors. A $p$-value $<.05$ was considered as the threshold for significance.

\section{Findings}

A total of 593 medical records of patients were studied over a period of 5 years, of which 59 (9.9\%) cases were excluded from the study due to incomplete records. Patients enrolled in this study included 324 males (60.68\%) and 210 females (39.32\%); also, 492 (92.1\%) cases were married, and 41 (7.9\%) cases were single. Most of the deaths occurred in the respiratory ICU with a frequency of $426(80 \%)$ and in the 
infectious diseases ward with a frequency of $108(20 \%)$. The mean age of the patients at the time of death was $70.9 \pm 17.8$ years, ranging from 18 to 114 years. Death was common in these two hospital wards among the elderly patients aged 80-90 years. The average length of hospitalization was 8.1 days, ranging from 1 to 94 days (Table 1); this variable did not follow a normal distribution, so did the patients' age. Out of 534 deaths, 183 (34.26\%) cases occurred after 2-6 days of hospitalization; however, 150 cases occurred on the first day of admission. In total, 150 patients (28.1\%) were hospitalized in the winter. The lowest prevalence of hospitalization was observed in the spring with 115 cases $(21.5 \%)$. There was no significant difference between the causes of death in terms of season $(p=.120)$. However, the prevalence of pneumonia in the autumn and winter was higher than in other seasons. Also, 70\% (378) of the patients lived in urban areas $(p=.414)$. The most common causes of death were sepsis 237 (44.3\%), pneumonia 135(25.3\%), stroke 37 (6.9\%), influenza 19

Table 1) Comparison of demographic characteristics of the patients admitted to the respiratory ICU and infectious ward

\begin{tabular}{|c|c|c|c|}
\hline Variable & $\begin{array}{l}\text { Respiratory ICU } \\
\text { N (\%) }\end{array}$ & $\begin{array}{l}\text { Infectious Ward } \\
\text { N (\%) }\end{array}$ & P Value \\
\hline \multicolumn{4}{|l|}{ Sex } \\
\hline Female & $164(38.5)$ & $46(46.6)$ & \multirow[t]{2}{*}{.436} \\
\hline Male & $262(61.5)$ & $62(57.4)$ & \\
\hline \multicolumn{4}{|l|}{ Habitat } \\
\hline City & 305 (71.6) & $73(67.6)$ & \multirow{3}{*}{.414} \\
\hline & & & \\
\hline Village & $121(28.4)$ & $35(32.4)$ & \\
\hline \multicolumn{4}{|l|}{ Underlying disease } \\
\hline Yes & $222(52.1)$ & $63(58.3)$ & \multirow{3}{*}{.247} \\
\hline & & & \\
\hline No & $204(47.9)$ & $45(41.7)$ & \\
\hline \multicolumn{4}{|l|}{ Seasons } \\
\hline Spring & 89 (20.9) & $26(24.1)$ & \multirow{4}{*}{.12} \\
\hline Summer & $96(22.5)$ & $33(30.6)$ & \\
\hline Autumn & $120(28.2)$ & $20(18.5)$ & \\
\hline Winter & $121(28.4)$ & $29(26.8)$ & \\
\hline Mean age \pm SD (yrs) & $70.2 \pm 18.3$ & $73.9 \pm 15.10$ & .124 \\
\hline Mean duration of hospitalization \pm SD (days) & $8.6 \pm 10.6$ & $6.7 \pm 11.6$ & .004 \\
\hline
\end{tabular}


(3.6\%), and other causes 51 (9.5\%), including renal failure, fulminant hepatitis, heart attack, and empyema (Table 2).

Moreover, 285 (53.4\%) patients had at least an underlying disease (hypertension, stroke, diabetes, heart disease, AIDS (Acquired immune deficiency syndrome), hepatitis, and COPD (Chronic obstructive pulmonary disease). There was no

Table 2) Distribution of the patients admitted to the respiratory ICU and infectious ward based on the causes of death

\begin{tabular}{|c|c|}
\hline Causes of Death & Number (\%) \\
\hline Sepsis & $237(44.3)$ \\
\hline Urosepsis & $21(3.9)$ \\
\hline Pneumosepsis & $40(7.5)$ \\
\hline Unknown origin & $176(32.9)$ \\
\hline Pneumonia & $135(25.3)$ \\
\hline Stroke & $37(6.9)$ \\
\hline Influenza & $19(3.6)$ \\
\hline Drug toxicity & $17(3.3)$ \\
\hline Tuberculosis & $16(3)$ \\
\hline Pulmonary embolism & $15(2.8)$ \\
\hline Meningitis & $5(0.9)$ \\
\hline Unknown & $2(0.4)$ \\
\hline Others* & $51(9.5)$ \\
\hline Total & $534(100)$ \\
\hline
\end{tabular}

* Renal failure, Fulminant Hepatitis, Empyema, Encephalitis, Myocardial infraction, Disseminated intravascular coagulopathy, Gastroenteritis.

statistically significant difference between the patients with underlying diseases and patients without underlying disease in terms of the causes of death $(p=.247)$. However, patients with an underlying illness died more often due to sepsis. Based on the findings of this study, no significant difference was found between the patients admitted to the respiratory intensive care unit and infectious ward in terms of age, sex, place of residence, season, and underlying illness; however, the duration of patients hospitalization in the ICU was significantly longer than in the infectious ward $(p=.004)$. Sepsis (48.2\%) and pulmonary embolism (44.1\%) accounted for the highest rates of case fatality; as nearly $50 \%$ of patients died due to sepsis. Table 3 shows that respiratory ICU patients mostly died because of sepsis and influenza, and the most common cause of death in the infectious ward was pneumonia. Besides, there was a statistically significant difference between the patients hospitalized in the ICU and infectious ward in terms of the causes of death $(p=.001)$.

\section{Discussion}

Different studies on infectious diseases in hospitals have demonstrated that sepsis and pneumonia were the most common causes of mortality [6,10-11]. Also, Fernandez et al. (1999) and TavanaeeSani et al. (2011) showed that pneumonia was the most common cause of hospitalization in elderly patients ${ }^{[6,8]}$. Another study by Golsha et al. (2012) showed that $25 \%$ of mortality in elderly patients was due to pneumonia [11]. However, in the present study, the main cause of death was sepsis in addition to pneumonia, inconsistent with the previous studies results [9-11]. Similar to this study findings, Hasibi et al. (2008) also reported sepsis and pneumonia as the main leading causes of death in patients ${ }^{[12]}$. It is suggested that some crucial steps be taken in order to assist in reducing the mortality rate, such as paying more attention to symptoms, urgent and accurate diagnosis, patient 
Table 3) Distribution of causes of death in the patients based on the admission wards

\begin{tabular}{llll}
\hline Causes of Death & $\begin{array}{l}\text { Infectious Ward } \\
\text { N (\%) }\end{array}$ & $\begin{array}{l}\text { Respiratory ICU } \\
\text { N (\%) }\end{array}$ & P Value \\
\hline Sepsis & $36(33.3)$ & $201(47.2)$ & $92(21.6)$ \\
\hline Pneumonia & $43(39.8)$ & $26(6.1)$ & .001 \\
\hline CVA & $11(10.2)$ & $19(4.5)$ & $88(20.6)$ \\
\hline Influenza & $0(0.0)$ & $426(100)$ \\
\hline Tothers & $18(16.7)$ & $108(100)$ & \\
\hline
\end{tabular}

* Renal failure, Fulminant Hepatitis, Empyema, Encephalitis, Myocardial infraction, Disseminated intravascular coagulopathy, Gastroenteritis.

hospitalization in the appropriate section based on the symptoms and severity of the disease, and early antibiotic therapy. It is clear that the nature and type of infectious diseases, duration of symptoms, and the late referral of patients are contributing factors that could increase the risk of patients' mortality. Since this study showed that case fatality rate was relatively high in patients with sepsis (48.2\%) and pulmonary embolism (44.1\%), and almost half of these patients died, it is necessary to take more precautions in order to reduce case fatality rate by early diagnosis and immediate treatment of these patients.

In the present study, the highest mortality rate was $80 \%$ in the intensive care unit, followed by $20 \%$ in the infectious ward. However, Mahmoudi et al. (2014) reported that most of the deaths occurred in the emergency department (45.7\%) and ICU $(30.4 \%)^{[13]}$. In another study by Noorizad et al. (2005), the highest morbidity rates were related to urinary tract infection (41.6\%) and pneumonia (28.5\%), these results are in line with the results of the present study in which mortality rate due to pneumonia was $21.6 \%$ in ICU ${ }^{[14]}$.

In this study, the mean age of the patients was approximately 70 years, and 50\% of the patients were over 76 years old $(p=0.124)$. It is worth mentioning that in the elderly, the presence of some infectious diseases like pneumonia may not be accompanied by symptoms of respiratory tract infection or even fever. These patients may be hospitalized with delirium and loss of consciousness. It is simply because in the elderly, the signs and symptoms of many infections are not the same as the symptoms of similar diseases in adults. The temperature in pneumococcal pneumonia is lower in the elderly than in young patients, and cough, fever, and sputum may not be present in these patients ${ }^{[15-17]}$. Also, it was determined that more than half of the patients who died in the infectious diseases ward and respiratory ICU had an underlying illness such as diabetes mellitus or previous cerebrovascular incidence. Noorizad et al. (2005) indicated in their study that underlying disease was associated with an increased risk of mortality ${ }^{[14]}$.

In this study, the majority of deaths were in males, which is approximately proportional to the general population of the country and also corresponding to the statistics of patients admitted to the ward of infectious 
diseases. Similar results were reported by Hasibi (2008), Serraino (2004), and Tellioğlu (2018) $^{[12,18-19] .}$.

The average length of hospitalization was 8 days in this study with the medians of 5 and 3 days for hospitalization in the ICU and infectious ward, respectively. In the present study, patients admitted to the respiratory ICU had a longer hospitalization period than those in the infectious ward because the severity of illnesses was lower among patients in the infectious diseases ward. In a study by Capelastegui (2008), more than $50 \%$ of patients with pneumonia were hospitalized for 5-10 days, which was similar to this study finding ${ }^{[20]}$. Timely prevention and control of these infectious diseases are suggested as the most effective approach for reducing the mortality rate.

\section{Conclusion}

According to this study findings, the increase in the length of hospitalization was highly correlated with the increase in the mortality rate in both wards. Providing timely and accurate treatment in order to reduce duration of hospitalization is a key factor to reduce the mortality rate in these two wards of Sina Hospital.

Acknowledgments: The authors would like to hereby declare that the investigations described in the present paper are part of the research performed by Dr. Sima Sadat Ahmadinejad's thesis (the second author of this paper) for Doctor of Medicine degree with contract number of 9602191102. Ethical Permissions: Approval number in Hamadan university of medical sciences is IR.UMSHA.REC.1396.119 .

Conflict of interest: There is no conflict of interest to be stated.

Authors Contribution: Conceptualization:

FK, SSA; Data curation: SSA; Formal analysis: ZS; Investigation: FK; Methodology:SSA; Project administration: FK; Resources: Supervision: FK; Validation: FK; Visualization: SSA;

Writing-original draft: AS; Writingreveiw and editing: AS.

Fundings: Hamadan university of medical sciences.

Consent to participate: Not applicable.

\section{References}

1. Kasper DL, Madoff LC. Introduction to infectious diseases: Host-pathogen interactions. In: Kasper DL, Fauci AS, Hauser SL, Longo DL, Jameson JL, Loscalzo J, editors. Harrison's principles of internal medicine. $19^{\text {th }}$ ed. New York: McGraw Hill Education; 2015. p. 1007-12.

2. Gupta I, Guin P. Communicable diseases in the South-East Asia region of the World Health Organization: Towards a more effective response. Bull World Health Organ.2010; 88(3):199-205.

3. Boutayeb A, Boutayeb S. The burden of non communicable diseases in developing countries. Int J Equity Health. 2005;4(1):2. Published 2005 Jan 14. doi:10.1186/1475-9276-4-2 .

4. Lankarani KB, Alavian SM, Peymani P. Health in the Islamic Republic of Iran, challenges and progresses. Med J Islam Repub Iran. 2013; 27(1):42-9.

5. Wester AL, Dunlop O, Melby KK, Dahle UR, Wyller TB. Age-related differences in symptoms, diagnosis, and prognosis of bacteremia. BMC Infect Dis. 2013; 13(1):346.

6. Fernández de la $\mathrm{Hoz} \mathrm{K}$, de Mateo $\mathrm{S}$, Regidor E. Trends in infectious diseases mortality in Spain. Gac Sanit. 1999; 13(4):256-62.

7. Dore GJ, Li Y, Plant AJ, Kaldor JM. Trends in infectious disease mortality in Australia, 1979-1994. Med J Aust. 1998; 168(12):601-4.

8. TavanaeeSani A, Mirkarimi H. Evaluation of etiology of infectious diseases in elderly 
patients admitted to the infectious ward of Imam Reza hospital. Med J Mashhad Univ Med Sci, 2011; 54(1):31-37.

9. Mouton CP, Bazaldua OV, Pierce B, Espino DV. Common infections in older adults. Am Fam Physician. 2001; 63(2):257-68.

10. Armstrong GL, Conn LA, Pinner RW. Trends in infectious disease mortality in the United States during the 20th century. JAMA. 1999; 281(1):61-6.

11. Golsha R, Golshah E, Jalali Z, Rajabli N, Roshandel G. Final diagnosis and outcomes in old patients admitted to the infectious diseases ward. Med J Mashhad Univ Med Sci. 2012; 55(3):158-63.

12. Hasibi M, Soudbakhsh A, Abadi Z, Mehdipoor P. Mortality rate of infectious disease in relation to holidays: Three year study in Imam Khomeini hospital. Tehran Univ Med J. 2008; 65(10):50-4

13. Mahmoudi GA, Astaraki P, Anbari K, Khayatpisheh S. Epidemiolgical survey of mortality rate in patients admitted to Shohada hospital of Khorramabad in 2011. Iran J Forensic Med. 2014; 20(1):393-400

14. Noorizad S, Tabesh H, Mahdian M, Akbari $\mathrm{H}$, Taghadosi M. Causes of mortality and morbidity in a neurosurgery ICU in Kashan
1999-2001. Feyz. 2005; 9(2):15-20

15. Norman DC, Grahn D, Yoshikawa TT. Fever and aging. J Am Geriatr Soc. 1985; 33(12):859-63.

16. Norman DC, Yoshikawa TT. Fever in the elderly. Infect Dis Clin North Am. 1996; 10(1):93-9.

17. Almario CV, Metz DC, Haynes K, Yang YX. Risk of community-acquired pneumonia in patients with a diagnosis of pernicious anemia: A populationbased retrospective cohort study. Eur J Gastroenterol Hepatol. 2015; 27(11):1259-64.

18. Serraino D, Bidoli E, Piselli P, Angeletti C, Bruzzone S, Pappagallo $\mathrm{M}$, et al. Time trends in infectious disease mortality in Italy: 1969-1999. Epidemiol Prev. 2004; 28(6):322-9.

19. Tellioğlu E, Balcı G, Mertoğlu A. Duration of stay of patients with communityacquired pneumonia in influenza season. Turk Thorac J. 2018; 19(4):182-6.

20. Capelastegui A, España PP, Quintana JM, Gallarreta M, Gorordo I, Esteban C, et al. Declining length of hospital stay for pneumonia and postdischarge outcomes. Am J Med. 2008;121(10):845-52. 